
para características dos frutos. Horticultura Brasileira 35: 180-185. DOI - http://dx.doi.org/10.1590/S0102-053620170205

\title{
Desempenho agronômico de híbridos experimentais de abóbora Tetsukabuto para características dos frutos
}

\section{Geovani B Amaro; Giovani O Silva; Leonardo S Boiteux; Agnaldo DF Carvalho; José F Lopes}

Embrapa Hortaliças, Brasília-DF, Brasil; geovani.amaro@embrapa.br; giovani.olegario@embrapa.br; leonardo.boiteux@embrapa.br; agnaldo.carvalho@embrapa.br; jose.lopes@embrapa.br

\section{RESUMO}

O cultivo de abóboras (Cucurbita moschata) e morangas (Cucurbita maxima) apresenta grande importância econômica e social no Brasil. Nas últimas décadas, a região do Brasil Central tem se consolidado como um polo emergente de cultivo e comercialização dessas hortaliças. Dentre as cultivares mais comercializadas no país se destaca o híbrido interespecífico conhecido como 'Tetsukabuto' ou 'Cabotiá' originado entre o cruzamento de uma linhagem feminina de C. maxima com uma linhagem masculina de C. moschata. O objetivo do trabalho foi avaliar o desempenho agronômico de híbridos experimentais interespecíficos tipo Tetsukabuto em condições do Planalto Central do Brasil por meio da avaliação direta e a correlação entre as características dos frutos. Foi avaliado um conjunto de 35 combinações híbridas interespecíficas (C. maxima x C. moschata), empregando como linhagem maternal elite a moranga CNPH 0739 que foi cruzada com uma coleção de 35 linhagens de abóboras. O experimento foi conduzido em condições de campo em Brasília-DF. Foram avaliados a produtividade total de frutos, o número de frutos por planta, massa média de frutos, comprimento e largura dos frutos, teor de sólidos solúveis, espessura da polpa e da casca dos frutos. $\mathrm{O}$ rendimento foi positivamente correlacionado com maior número de frutos por planta, maior massa, maior espessura de polpa e maior largura de frutos. Plantas com frutos de maior massa apresentaram menores teores de sólidos solúveis. O híbrido experimental $\mathrm{CNPH}$ 2377 destacou-se para as características avaliadas e apresentou alta produtividade de frutos com 21,98 t/ha, com peso médio acima de $3 \mathrm{~kg}$, cerca de 4 frutos por planta, com polpa espessa $(34,41 \mathrm{~mm})$, casca fina $(2,17 \mathrm{~mm})$ e razoável teor de sólidos solúveis $\left(17,01^{\circ} \mathrm{Brix}\right)$. Assim, a maior produtividade foi cerca de duas vezes superior àquela do híbrido Jabras (testemunha comercial). Neste contexto, os resultados, obtidos no presente experimento, indicam boas perspectivas no sentido de se obter materiais genéticos do segmento varietal Tetsukabuto, combinando características agronômicas de interesse e melhor aptidão para o cultivo no Brasil Central.

Palavras-chave: Cucurbita maxima, Cucurbita moschata, melhoramento genético, produção, qualidade.

\begin{abstract}
Agronomic performance of pumpkin type Tetsukabuto hybrids for fruits traits

Pumpkins and squashes (Cucurbita moschata and Cucurbita maxima) are important crops in Brazil. In the recent decades, Central Brazil is increasing its importance as a cucurbit-producing region. An interspecific hybrid known as 'Tetsukabuto' or 'Cabotiá', originated from a cross between a $C$. maxima female inbred line and a $C$. moschata male inbred line stands out among the most commercialized varieties in the Country. The objective was to evaluate the agronomic performance of experimental interspecific Tetsukabuto hybrids through direct evaluation and through the correlation between fruit characteristics, in Central Plateau of Brazil. Eight fruit traits were evaluated in 35 interspecific experimental hybrid combinations in a field assay carried out in Brasília. These hybrids were derived from crosses involving the elite C. maxima inbred line CNPH 0739 and 35 C. moschata inbred lines. The characteristics evaluated were total fruit yield, number of fruits per plant, average fruit weight, length and diameter of fruit, soluble solids content, fruit pulp thickness and shell thickness. Fruit yield was found to be positively correlated with a higher number of fruits per plant, higher average fruit weight, higher flesh thickness and higher fruit diameter. However, no significant correlation was observed with fruit length. Fruits with the highest average weight displayed lower ${ }^{\circ}$ Brix. The experimental hybrid CNPH 2377 stood out for the characteristics and showed high productivity of fruits (21.98 t/ha), average fruit weight over 3 $\mathrm{kg}$, about 4 fruits per plant, with thick pulp $(34.41 \mathrm{~mm})$, thin shell $(2.17 \mathrm{~mm})$ and acceptable content of soluble solids (17.01 $\left.{ }^{\circ} \mathrm{Brix}\right)$. In this context, our results indicated that it is feasible to develop new genetic materials from the variety group Tetsukabuto, combining superior agronomic traits as well as adaptation to the highland areas of Central Brazil.
\end{abstract}

Keywords: Cucurbita maxima, Cucurbita moschata, breeding, production, quality.

(Recebido para publicação em 11 de janeiro de 2016; aceito em 22 de setembro de 2016) (Received on January 11, 2016; accepted on September 22, 2016)

\begin{abstract}
A família Cucurbitaceae engloba cerca de 90 gêneros e mais de 800 espécies de plantas, muitas das quais adaptadas às regiões tropicais e subtropicais (Bee \& Barros, 1999). O
\end{abstract}

gênero Cucurbita (nativo das Américas) é considerado, em todo o reino vegetal, como um dos mais diversificados em termos de morfologia/arquitetura de planta e características dos frutos. O nú- mero constante e relativamente elevado de cromossomos $(2 n=40)$ observado nas diferentes espécies de Cucurbita sugere a origem do gênero por meio de alopoliploidia (Bisognin, 2002). 
Assim, pressupõe que são indivíduos com genoma formado por dois ou mais conjuntos de cromossomos oriundos de espécies distintas. Dentre as espécies domesticadas, C. moschata, C. maxima e C. pepo, encontram-se entre as mais importantes cucurbitáceas do ponto de vista socioeconômico e também para a nutrição humana. As abóboras $(C$. moschata) e as morangas (C. maxima) são consideradas valiosas fontes de fibras alimentares, carboidratos, minerais, vitaminas do complexo B e carotenoides antioxidantes com ação de provitamina A, tais como alfa-caroteno e luteína (Boiteux et al., 2007).

Os dados referentes à produção nacional destas hortaliças são escassos. Segundo o IBGE (2006), a produção brasileira de abóbora foi de 384.912 $\mathrm{t}$ de frutos maduros em uma área de 88.150 ha gerando uma produtividade em torno de 4,37 t/ha. Entre os fatores responsáveis por esses baixos níveis de produtividade se encontram o cultivo de populações heterogêneas associado com a baixa disponibilidade de variedades adaptadas às diferentes condições edafoclimáticas do Brasil (Almeida et al., 1994).

No Brasil, muitas introduções de espécies da família Cucurbitaceae têm sido mantidas in situ por iniciativa espontânea de produtores rurais em diferentes sistemas de produção e representam um valioso recurso genético (Queiroz, 2004). A exploração genética dessas landraces ou variedades crioulas de Cucurbita pode permitir a ampliação da diversidade fenotípica e genética do germoplasma destinado ao uso em programas de melhoramento genético dessas espécies (Queiroz, 2004). No gênero Cucurbita, os cruzamentos interespecíficos têm sido explorados como uma estratégia eficaz para potencializar características positivas de interesse agronômico bem como maximizar a heterose. Yongan et al. (2002b) estudaram a hibridação interespecífica entre quatro espécies do gênero Cucurbita e sugeriram que a espécie C. maxima pode ser usada como fonte para introgredir caracteres desejáveis entre espécies, pois os cruzamentos interespecíficos C. moschata $C$. maxima e C. argyrosperma $x$ C. maxima, além de se mostrarem compatíveis, geraram progênies heteróticas. Yongan et al. (2002a) observaram que existem algumas barreiras de cruzamento e diferentes níveis de afinidade na hibridação sexual entre linhagens endogâmicas de C. maxima e C. moschata. A melhor expressão de afinidade genética entre acessos foi definida pela característica número de sementes normais por fruto e que diferiu amplamente de acordo com as linhagens empregadas nos experimentos. Resultados semelhantes foram obtidos por Karaağaç \& Balkaya (2013) em avaliações envolvendo diferentes combinações interespecíficas entre linhagens de C. maxima e C. moschata. Os cruzamentos entre acessos dessas duas espécies apresentaram distintos graus de fertilização de acordo com a estrutura genética das linhagens utilizadas no processo de hibridação (Karaağaç \& Balkaya, 2013).

As abóboras híbridas do segmento varietal Tetsukabuto (também conhecidas como abóbora japonesa ou Cabotiá) são provenientes do cruzamento de linhagens selecionadas de C. maxima e C. moschata. Esse segmento lidera a preferência de mercado nas regiões Sul, Sudeste e Centro-Oeste do Brasil. Essas abóboras são produzidas em todas as regiões do Brasil. No entanto, nas últimas décadas, o Brasil Central tem se consolidado como um polo emergente de cultivo e comercialização, com especial destaque para as regiões produtoras de Jaíba/Manga-MG, São Desidério-BA, Paracatu-MG (Miranda, 2012) e Anápolis-GO. A liderança comercial desses híbridos interespecíficos se deve a uma maior rusticidade, maiores níveis de produtividade, precocidade, uniformidade, qualidade organoléptica e pós-colheita superior quando comparados com cultivares de polinização aberta (Nascimento et al., 2008). O alto volume de importação de sementes de abóbora híbrida no País ressalta a importância de pesquisas que visem o desenvolvimento de tecnologias genéticas para a produção destas sementes no Brasil (Costa et al., 2006).

Neste contexto, o presente trabalho teve como objetivo avaliar o desempenho agronômico de híbridos experimentais interespecífico tipo Tetsukabuto em condições do Planalto Central do Brasil por meio da avaliação direta e a correlação entre as características dos frutos.

\section{MATERIAL E MÉTODOS}

Foram avaliados 35 híbridos experimentais originados de cruzamentos (com estrutura do tipo 'topcross') entre a linhagem elite 'CNPH 0739' $C$. maxima (moranga, usada como genitor feminino) e 35 linhagens da espécie C. moschata (abóboras, usadas como genitores masculinos). Como testemunha utilizou-se o híbrido comercial 'Jabras' (Sementes Hortec, Bragança Paulista-SP e Embrapa Hortaliças, Brasília-DF). O delineamento experimental foi em blocos casualizados com três repetições. A parcela foi constituída de uma linha com cinco plantas, utilizando-se o espaçamento de $1,5 \mathrm{~m}$ entre plantas, $4,0 \mathrm{~m}$ entre linhas e 2,0 $\mathrm{m}$ entre parcelas. Como polinizadoras foram utilizadas (entre as parcelas) duas plantas da moranga 'Exposição'. O experimento foi instalado em 25 de setembro de 2013, no campo da Embrapa Hortaliças (15⒌ $5^{\prime} 54^{\prime \prime} \mathrm{S}, 48^{\circ} 08^{\prime} 29^{\prime \prime} \mathrm{O}$ ), em um Latossolo Vermelho-Amarelo distrófico. A análise química de fertilidade do solo apresentou os seguintes resultados: $\mathrm{pH}\left(\mathrm{H}_{2} \mathrm{O}\right)=5,2 ; \mathrm{H}+\mathrm{Al}=8,2$ $\mathrm{cmol}_{\mathrm{c}} / \mathrm{dm}^{3} ; \mathrm{Ca}=2,7 \mathrm{cmol} / \mathrm{dm}^{3} ; \mathrm{Mg}=1,3$ $\mathrm{cmol}_{\mathrm{c}} / \mathrm{dm}^{3} ; \mathrm{P}($ Mehlich $)=23,3 \mathrm{mg} / \mathrm{dm}^{3}$; $\mathrm{K}=0,74 \mathrm{cmol} / \mathrm{dm}^{3}$; matéria orgânica $=$ $46,6 \mathrm{~g} / \mathrm{dm}^{3} ; \mathrm{CTC}=12,98 \mathrm{cmol}_{\mathrm{c}} / \mathrm{dm}^{3} ; \mathrm{V}=$ $36,83 \%$. Foi realizada uma calagem 80 dias antes do plantio com a aplicação de calcário dolomítico na dose de 2,5 t/ha. O preparo do solo foi realizado com uma aração, duas gradagens e a construção de sulcos com $30 \mathrm{~cm}$ de largura e $20 \mathrm{~cm}$ de profundidade. A adubação de plantio foi de $400 \mathrm{~kg} / \mathrm{ha}$ com a formulação NPK 0828-16, distribuída no sulco de plantio. As mudas utilizadas foram produzidas em bandejas de polipropileno de 72 células e transplantadas 15 dias após o semeio. Foram realizadas duas adubações de cobertura com a formulação 20-00-20, na dose de $100 \mathrm{~kg} / \mathrm{ha}$, aos 25 e 45 dias após o transplante. Durante o desenvolvimento, na ausência de chuvas, realizaram-se irrigações semanais via sistema de aspersão convencional 
com lâmina de $30 \mathrm{~mm}$ e duas aplicações de fungicida associado a inseticida até o aparecimento dos frutos. A colheita realizou-se no dia 19 de dezembro de 2013, 85 dias após o transplante.

Foram avaliadas as seguintes características: produtividade total de frutos (PTF) (t/ha); número de frutos/planta (NFP); massa média dos frutos (MMF) $(\mathrm{kg})$; e, pelo valor médio da avaliação de três frutos: comprimento dos frutos (CFR) (cm); largura dos frutos (LFR) $(\mathrm{cm})$, obtida pela medida transversal com paquímetro do terço superior dos frutos; teor de sólidos solúveis (TSS) em ( ${ }^{\circ}$ Brix), determinados a partir da exsudação ocorrida pela quebra do pedúnculo dos frutos, que foi colocada no prisma do refratômetro; espessura da polpa (EP) e espessura da casca (EC) (em $\mathrm{mm}$ ) obtidas a partir da medição realizada com paquímetro após o corte transversal dos frutos no terço superior.

Os dados foram submetidos à análise de variância e os valores médios obtidos foram agrupados por meio do teste Scott-Knott ao nível de 5\% de probabilidade. Foram estimados os valores dos coeficientes de variação fenotípicos (CV), bem como os valores da relação entre os coeficientes de variação genotípicos e fenotípicos $(\mathrm{CVg} / \mathrm{CV})$ entre caracteres, empregando o programa estatístico Genes (Cruz, 2006).

\section{RESULTADOS E DISCUSSÃO}

Diferenças significativas, ao nível de $5 \%$ de probabilidade pelo teste $\mathrm{F}$, foram observadas entre os 35 híbridos experimentais para todas as características avaliadas. Os coeficientes de variação fenotípicos (CV) foram maiores para as seguintes variáveis: produtividade total de frutos (PTF), número de frutos por planta (NFP) e massa média de frutos (MMF), 25,54, 24,65 e 20,60, respectivamente (Tabela 1). Essas faixas de valores se equivalem aos usualmente encontrados para estas características em híbridos do segmento Tetsukabuto, reportados na literatura. Almeida et al. (1994) reportaram CV de 35\% para a característica NFP. Amaro et al. (2012) verificaram CV de $24,09 \%$ para número de frutos por parcela, $24,12 \%$ para pro- dução de frutos por parcela e 40,71\% para MMF. Pasqualetto et al. (2001) obtiveram valores de $16,02 \%$ para NFP, $30,93 \%$ para MMF e $30,89 \%$ para produção de frutos por planta.

Para a maioria das características avaliadas, o valor da relação entre o coeficiente de variação genotípico e fenotípico $(\mathrm{CVg} / \mathrm{CV})$ foi superior ou próximo à unidade, indicando predominância de variação de ordem genética na manifestação das características bem como confiabilidade na seleção. Uma situação oposta foi verificada para a característica TSS, que apresentou maior variação fenotípica em relação à genotípica (Tabela 1). Desta forma, somado ao fato de ter apresentado reduzido valor de $\mathrm{CV}$, podemos concluir que existe baixa variabilidade genética entre os híbridos avaliados para essa importante característica de qualidade de fruto. Bezerra Neto et al. (2006) verificaram para sete linhagens de abóboras (C. moschata), predominância do $\mathrm{CVg}$ sobre o CV para a característica MMF, porém predominância do $\mathrm{CV}$ para os caracteres NFP, LFR, CFR, EP e EC.

Uma análise das correlações genotípicas entre as características indicou que PTF se correlaciona positivamente com a LFR e a EP, além da associação positiva com NFP e MMF (Tabela 2). No entanto, PTF não se correlaciona com o CFR, indicando que para a obtenção de frutos mais compridos se faz necessário conduzir o processo de seleção para esta característica em separado. Por sua vez, a característica MMF correlaciona-se positivamente com os caracteres CFR, LFR e EP, indicando situação favorável à seleção para múltiplos caracteres de interesse. Além disso, essas correlações facilitariam o processo de avaliação, uma vez que o caráter MMF é de mais fácil mensuração que os demais. Um aspecto negativo do ponto de vista do melhoramento genético para qualidade de fruto e produtividade foi a correlação negativa entre MMF e TSS. A característica TSS correlacionou-se negativamente também com CFR, LFR e EP, indicando que na seleção de frutos maiores pode haver um impacto negativo no ${ }^{\circ}$ Brix dos frutos. Uma possível explicação para essa correlação poderia ser um "efeito de diluição" dos sólidos solúveis nas plantas com maior massa de polpa (= frutos grandes). O TSS apresentou, por sua vez, uma correlação positiva com NFP, o que pode estar relacionado com a correlação negativa entre MMF e NFP, ou seja, quanto maior o número de frutos por planta, menor o tamanho dos frutos e, por consequência, maior o valor de medição do TSS (Tabela 2). Bezerra Neto et al. (2006) avaliaram linhagens de abóbora C. moschata e também observaram correlações genéticas negativas e significativas entre NFP e MMF; positivas e significativas entre EP com MMF e LFR, mas não com CFR, e entre MMF e LFR, concordando com o presente estudo. Os autores verificaram ainda correlação negativa significativa entre EP e NFR, e entre NFP e CFR; e correlação positiva significativa entre NFP e LFR. Essas correlações não foram observadas no presente trabalho.

A característica NFP variou de 0,67 a 5,53 para os híbridos experimentais e foi de 4,67 para o híbrido Jabras (Tabela 1). Estes valores estiveram relativamente próximos aos extremos mínimos e máximos encontrados por Maynard et al. (2002) em híbridos de C. moschata (2,2 a 4,3 frutos/planta), na Flórida-EUA, e por Resende et al. (2013) em acessos de C. moschata (3,5 a 4,6 unidades) e na cultivar Jacarezinho (4,7 unidades), em Petrolina-PE.

A característica MMF variou de 1,06 a 3,16 kg para os híbridos experimentais e foi de 1,46 para o híbrido Jabras. Nascimento et al. (2008), avaliando a eficiência de diferentes acessos de $C$. maxima como fontes de pólen para dois híbridos do tipo varietal Tetsukabuto, reportaram peso médio de frutos entre 1,19 e $1,35 \mathrm{~kg}$, para as combinações 'Jabras' $x$ 'Nirvana' e 'Tetsukabuto Kyoto' $x$ 'Exposição', respectivamente. Por sua vez, Amarante \& Macedo (2000) verificaram massa média de $2,49 \mathrm{~kg}$ em um híbrido do tipo Tetsukabuto.

Os valores médios de CFR e LFR foram de 17,44 e 16,28 cm respectivamente. Uma variação na largura de frutos de 12,42 a $20,30 \mathrm{~cm}$ foi observada em ensaios conduzidos em São Cristóvão-SE, utilizando como germoplasma uma cultivar comercial de abóbora (C. moschata), um híbrido de C. maxima, uma população melhorada de 
Tabela 1. Agrupamento de médias para características de fruto avaliadas em 35 híbridos interespecíficos (Cucurbita maxima x C. moschata) do segmento varietal Tetsukabuto \{grouping of mean values for a set of fruit traits evaluated in 35 interespecific hybrids (Cucurbita maxima x C. moschata) varietal group Tetsukabuto\}. Brasília, Embrapa, 2013.

\begin{tabular}{|c|c|c|c|c|c|c|c|c|}
\hline Híbridos experimentais & PTF & NFP & MMF & CFR & LFR & TSS & EP & EC \\
\hline CNPH 0002 & $9,90 \mathrm{c}$ & $3,67 \mathrm{a}$ & $1,62 \mathrm{c}$ & $17,33 \mathrm{c}$ & $16,89 a$ & $18,73 a$ & $27,91 \mathrm{c}$ & $2,86 \mathrm{~b}$ \\
\hline CNPH 0016 & $6,63 \mathrm{c}$ & $2,20 \mathrm{~b}$ & $1,85 \mathrm{c}$ & $13,89 \mathrm{c}$ & $16,67 \mathrm{a}$ & $17,93 b$ & $23,26 \mathrm{~d}$ & $2,94 \mathrm{~b}$ \\
\hline CNPH 0018 & $12,67 \mathrm{~b}$ & $4,87 \mathrm{a}$ & $1,52 \mathrm{c}$ & $14,44 \mathrm{c}$ & $17,78 \mathrm{a}$ & $18,89 \mathrm{a}$ & $26,33 \mathrm{c}$ & $3,46 \mathrm{a}$ \\
\hline CNPH 0056 & $7,36 \mathrm{c}$ & $3,87 \mathrm{a}$ & $1,14 \mathrm{c}$ & $16,78 \mathrm{c}$ & $15,00 \mathrm{~b}$ & $18,89 \mathrm{a}$ & $21,26 \mathrm{e}$ & $2,37 \mathrm{c}$ \\
\hline CNPH 0070 & $10,19 \mathrm{c}$ & $4,87 \mathrm{a}$ & $1,34 \mathrm{c}$ & $20,22 b$ & $14,22 b$ & $18,65 \mathrm{a}$ & $23,32 d$ & $3,31 \mathrm{a}$ \\
\hline CNPH 0091 & $6,79 \mathrm{c}$ & $1,60 \mathrm{~b}$ & $2,58 b$ & $20,89 b$ & $17,44 \mathrm{a}$ & $16,52 b$ & $29,56 b$ & $1,99 \mathrm{c}$ \\
\hline CNPH 0150 & $10,90 \mathrm{~b}$ & $4,47 \mathrm{a}$ & $1,61 \mathrm{c}$ & $18,22 \mathrm{c}$ & $16,56 \mathrm{a}$ & $18,33 \mathrm{a}$ & $27,08 \mathrm{c}$ & $1,63 \mathrm{c}$ \\
\hline CNPH 0151 & $9,58 \mathrm{c}$ & $3,87 \mathrm{a}$ & $1,50 \mathrm{c}$ & $14,11 \mathrm{c}$ & $17,56 \mathrm{a}$ & $17,49 b$ & $26,76 \mathrm{c}$ & $2,76 b$ \\
\hline CNPH 0153 & $11,51 \mathrm{~b}$ & $4,80 \mathrm{a}$ & $1,44 \mathrm{c}$ & $14,89 \mathrm{c}$ & $17,67 \mathrm{a}$ & $17,33 b$ & $27,13 \mathrm{c}$ & $2,36 \mathrm{c}$ \\
\hline CNPH 0179 & $8,73 \mathrm{c}$ & $3,20 \mathrm{a}$ & $1,59 \mathrm{c}$ & $15,00 \mathrm{c}$ & $17,33 a$ & $18,62 \mathrm{a}$ & $30,75 b$ & $2,38 \mathrm{c}$ \\
\hline CNPH 0180 & $9,34 \mathrm{c}$ & $4,67 \mathrm{a}$ & $1,21 \mathrm{c}$ & $12,78 \mathrm{c}$ & $16,33 a$ & $18,99 \mathrm{a}$ & $25,27 d$ & $2,10 \mathrm{c}$ \\
\hline CNPH 0182 & $8,51 \mathrm{c}$ & $4,40 \mathrm{a}$ & $1,16 \mathrm{c}$ & $13,67 \mathrm{c}$ & $15,67 \mathrm{~b}$ & $16,10 \mathrm{~b}$ & $26,37 \mathrm{c}$ & $2,31 \mathrm{c}$ \\
\hline CNPH 0184 & $12,01 \mathrm{~b}$ & $4,40 \mathrm{a}$ & $1,64 \mathrm{c}$ & $13,67 \mathrm{c}$ & $17,33 a$ & $21,33 a$ & $29,55 b$ & $2,97 \mathrm{~b}$ \\
\hline CNPH 0185 & $9,87 \mathrm{c}$ & $4,93 \mathrm{a}$ & $1,18 \mathrm{c}$ & $13,11 \mathrm{c}$ & $16,89 \mathrm{a}$ & $19,56 \mathrm{a}$ & $27,55 \mathrm{c}$ & $2,77 \mathrm{~b}$ \\
\hline CNPH 0200 & $9,99 \mathrm{c}$ & $4,80 \mathrm{a}$ & $1,25 \mathrm{c}$ & $15,00 \mathrm{c}$ & $16,00 \mathrm{a}$ & $20,45 a$ & $28,79 \mathrm{c}$ & $2,43 \mathrm{c}$ \\
\hline CNPH 0209 & $10,05 \mathrm{c}$ & $4,07 \mathrm{a}$ & $1,49 \mathrm{c}$ & $16,78 \mathrm{c}$ & $16,67 \mathrm{a}$ & $18,64 \mathrm{a}$ & $29,82 b$ & $3,28 \mathrm{a}$ \\
\hline CNPH 0220 & $11,39 b$ & $4,13 \mathrm{a}$ & $1,66 \mathrm{c}$ & $15,78 \mathrm{c}$ & $17,22 \mathrm{a}$ & $19,39 a$ & $28,95 \mathrm{c}$ & $2,34 \mathrm{c}$ \\
\hline CNPH 0223 & $9,13 \mathrm{c}$ & $4,93 \mathrm{a}$ & $1,10 \mathrm{c}$ & $14,11 \mathrm{c}$ & $16,22 \mathrm{a}$ & $19,07 \mathrm{a}$ & $24,27 \mathrm{~d}$ & $3,37 \mathrm{a}$ \\
\hline CNPH 0224 & $10,32 \mathrm{c}$ & $4,60 \mathrm{a}$ & $1,45 \mathrm{c}$ & $15,11 \mathrm{c}$ & $16,78 \mathrm{a}$ & $19,22 \mathrm{a}$ & $27,76 \mathrm{c}$ & $2,31 \mathrm{c}$ \\
\hline CNPH 0501 & $7,57 \mathrm{c}$ & $1,93 b$ & $2,42 b$ & $23,89 \mathrm{a}$ & $18,55 \mathrm{a}$ & $15,21 \mathrm{~b}$ & $30,94 b$ & $2,63 b$ \\
\hline CNPH 0543 & $7,80 \mathrm{c}$ & $3,33 \mathrm{a}$ & $1,39 \mathrm{c}$ & $13,66 \mathrm{c}$ & $16,89 \mathrm{a}$ & $19,67 \mathrm{a}$ & $27,37 \mathrm{c}$ & $2,34 \mathrm{c}$ \\
\hline CNPH 1055 & $7,47 \mathrm{c}$ & $3,53 \mathrm{a}$ & $1,27 \mathrm{c}$ & $16,33 \mathrm{c}$ & $14,67 b$ & $21,25 \mathrm{a}$ & $20,07 \mathrm{e}$ & $2,66 \mathrm{~b}$ \\
\hline CNPH 1359 & $15,00 \mathrm{~b}$ & $4,07 \mathrm{a}$ & $2,17 b$ & $24,89 \mathrm{a}$ & $16,89 \mathrm{a}$ & $18,34 \mathrm{a}$ & $28,91 \mathrm{c}$ & $2,64 \mathrm{~b}$ \\
\hline CNPH 1519 & $7,38 \mathrm{c}$ & $4,13 \mathrm{a}$ & $1,06 \mathrm{c}$ & $18,78 \mathrm{~b}$ & $12,78 \mathrm{c}$ & $19,78 \mathrm{a}$ & $20,24 \mathrm{e}$ & $2,54 \mathrm{c}$ \\
\hline CNPH 1525 & $7,97 \mathrm{c}$ & $3,53 \mathrm{a}$ & $1,48 \mathrm{c}$ & $21,89 \mathrm{~b}$ & $14,78 \mathrm{~b}$ & $16,67 b$ & $25,35 \mathrm{~d}$ & $2,27 \mathrm{c}$ \\
\hline CNPH 1535 & $8,80 \mathrm{c}$ & $3,80 \mathrm{a}$ & $1,44 \mathrm{c}$ & $22,89 \mathrm{a}$ & $12,89 \mathrm{c}$ & $19,33 a$ & $22,92 d$ & $2,42 \mathrm{c}$ \\
\hline CNPH 1713 & $8,36 c$ & $3,27 \mathrm{a}$ & $1,59 \mathrm{c}$ & $19,67 b$ & $17,00 \mathrm{a}$ & $19,22 \mathrm{a}$ & $29,95 b$ & $2,75 b$ \\
\hline CNPH 1816 & $7,09 \mathrm{c}$ & $3,93 \mathrm{a}$ & $1,11 \mathrm{c}$ & $17,44 \mathrm{c}$ & $14,44 b$ & $17,44 \mathrm{~b}$ & $26,32 \mathrm{c}$ & $2,29 \mathrm{c}$ \\
\hline CNPH 1960 & $13,87 \mathrm{~b}$ & $3,33 \mathrm{a}$ & $2,47 b$ & $26,56 \mathrm{a}$ & $17,89 a$ & $18,22 \mathrm{a}$ & $34,06 \mathrm{a}$ & $2,75 b$ \\
\hline CNPH 1966 & $10,41 \mathrm{c}$ & $5,00 \mathrm{a}$ & $1,24 \mathrm{c}$ & $21,28 b$ & $12,58 \mathrm{c}$ & $18,55 \mathrm{a}$ & $25,74 d$ & $1,68 \mathrm{c}$ \\
\hline CNPH 1981 & $1,50 \mathrm{c}$ & $0,67 b$ & $1,33 \mathrm{c}$ & $16,22 \mathrm{c}$ & $15,44 \mathrm{~b}$ & $17,44 b$ & $27,27 \mathrm{c}$ & $2,38 \mathrm{c}$ \\
\hline CNPH 1992 & $12,05 \mathrm{~b}$ & $3,13 \mathrm{a}$ & $2,27 b$ & $20,44 b$ & $18,33 \mathrm{a}$ & $15,67 \mathrm{~b}$ & $30,32 b$ & $3,01 \mathrm{~b}$ \\
\hline CNPH 2000 & $6,00 \mathrm{c}$ & $2,60 \mathrm{~b}$ & $1,38 \mathrm{c}$ & $17,11 \mathrm{c}$ & $15,78 \mathrm{a}$ & $18,44 \mathrm{a}$ & $26,79 \mathrm{c}$ & $2,40 \mathrm{c}$ \\
\hline CNPH 2315 & $12,23 b$ & $5,53 \mathrm{a}$ & $1,39 \mathrm{c}$ & $17,33 \mathrm{c}$ & $14,55 \mathrm{~b}$ & $19,37 \mathrm{a}$ & $26,73 \mathrm{c}$ & $2,56 \mathrm{c}$ \\
\hline CNPH 2377 & $21,98 \mathrm{a}$ & $4,20 \mathrm{a}$ & $3,16 \mathrm{a}$ & $19,45 b$ & $20,00 \mathrm{a}$ & $17,01 \mathrm{~b}$ & $34,41 \mathrm{a}$ & $2,17 \mathrm{c}$ \\
\hline Jabras & $11,48 b$ & $4,67 \mathrm{a}$ & $1,46 \mathrm{c}$ & $14,33 \mathrm{c}$ & $16,33 a$ & $17,94 \mathrm{~b}$ & $26,96 \mathrm{c}$ & $2,82 \mathrm{~b}$ \\
\hline Média & 9,77 & 3,86 & 1,58 & 17,44 & 16,28 & 18,44 & 27,11 & 2,56 \\
\hline CV (\%) & 25,54 & 24,65 & 20,6 & 16,13 & 7,94 & 8,41 & 9,49 & 13,66 \\
\hline $\mathrm{CVg} / \mathrm{CV}$ & 1,17 & 0,94 & 1,34 & 1,14 & 1,13 & 0,68 & 1,13 & 1,07 \\
\hline
\end{tabular}

$\mathrm{PTF}=$ produtividade total $(\mathrm{t} / \mathrm{ha})\{$ total fruit yield $(\mathrm{t} / \mathrm{ha})\} ; \mathrm{NFP}=$ número de frutos por planta (number of fruits per plant); $\mathrm{MMF}=$ massa média de frutos $(\mathrm{kg})$ fruit mass $(\mathrm{kg})\} ; \mathrm{CFR}=$ comprimento dos frutos $(\mathrm{cm})$ fruit length $(\mathrm{cm})\} ; \mathrm{LFR}=$ largura dos frutos $(\mathrm{cm})\{$ fruit width $(\mathrm{cm})\} ; \mathrm{TSS}=$ teor de sólidos solúveis $\left({ }^{\circ} \mathrm{Brix}\right)\left\{\right.$ total soluble solids $\left.\left({ }^{\circ} \mathrm{Brix}\right)\right\} ; \mathrm{EP}=$ espessura da polpa dos frutos (mm) $\{$ fruit pulp thickness $(\mathrm{mm})\} ; \mathrm{EC}=$ espessura da casca dos frutos $(\mathrm{mm})\{$ thickness of the fruit cortex $(\mathrm{mm})\}$. Médias seguidas pela mesma letra, na coluna, não diferem entre si pelo teste de Scott-Knott (5\%) \{means followed by the same letter in the column do not differ significantly from each other by the Scott-Knott test $(5 \%)\}$. CV= coeficiente de variação fenotípico (phenotypic coefficient of variation); $\mathrm{CVg}=$ coeficiente de variação genotípico (genotypic coefficient of variation). 
C. moschata e um genótipo experimental de C. moschata (Silva, 2010). Barbosa (2009) verificou em seis genótipos de abóbora que os comprimentos de frutos oscilaram entre 21,37 (frutos pequenos e arredondados) a 47,54 cm (frutos grandes com formato alongado).

As medidas do TSS variaram de 15,21 a $21,33^{\circ}$ Brix. O híbrido Jabras (utilizado como testemunha) apresentou $17,94^{\circ}$ Brix (Tabela 1 ). De acordo com Santos et al. (2012), os frutos são considerados de alta qualidade quando apresentam TSS mínimo de $17^{\circ}$ Brix. No presente ensaio, a maioria dos híbridos conseguiu superar este valor mínimo, havendo inclusive indicação de que são precoces em maturação. Segundo Irving et al. (1997), a fase de maturação de abóboras é caracterizada pelo declínio do teor de amido e de matéria seca com maior acumulação de glicose, sacarose e frutose.

O valor médio da $\operatorname{EP}(27,11 \mathrm{~mm})$ foi muito semelhante ao encontrado em experimentos conduzidos por Nascimento et al. (2008) com híbridos de abóbora tipo Tetsukabuto $(26,40 \mathrm{~mm})$. De acordo com Almeida et al. (1994), esta característica é de relevante importância pois maior porcentagem de polpa implica em maior aproveitamento do fruto. Com referência à característica $\mathrm{EC}$, Barbosa (2009) observou em linhagens e cultivares de abóbora uma variação entre 0,15 (linhagem L27) e 0,39 cm ('Menina Brasileira') na espessura de casca na região peduncular de frutos. Conforme este autor, frutos com epicarpo fino favorecem a perda de massa durante o armazenamento, tanto pela maior vulnerabilidade à injúria mecânica, como pela maior perda de água. Contudo, frutos com epicarpo delgado proporcionam maior rendimento em polpa. Portanto, são desejadas espessuras das cascas intermediárias que favorecem o armazenamento por períodos maiores sem prejudicar o rendimento da polpa.

A maior produtividade de frutos $(21,98 \mathrm{t} / \mathrm{ha})$ foi obtida do cruzamento entre a linhagem feminina ' $\mathrm{CNPH} 0739$ ' e a linhagem masculina 'CNPH 2377' (Tabela 1). Por exemplo, os níveis de produtividade reportados para o híbrido comercial 'Jabras' oscilam entre $12 \mathrm{e}$ 23 t/ha (Embrapa, 2014). Este híbrido

Tabela 2. Correlações genotípicas entre características de fruto avaliadas em 35 híbridos interespecíficos (Cucurbita maxima x C. moschata) para o segmento varietal Tetsukabuto \{genotypic correlations among fruit traits evaluated in 35 interespecific (Cucurbita maxima x C. moschata) Tetsukabuto type hybrids \}. Brasília, Embrapa, 2013.

\begin{tabular}{llclllll}
\hline & PTF & NFP & MMF & CFR & LFR & TSS & EP \\
\hline NFP & $0,50^{* *}$ & & & & & & \\
MMF & $0,57^{* *}$ & $-0,39 *$ & & & & & \\
CFR & 0,19 & $-0,26$ & $0,52^{* *}$ & & & & \\
LFR & $0,54^{* *}$ & $-0,24$ & $0,76^{* *}$ & $-0,10$ & & & \\
TSS & $-0,09$ & $0,52^{* *}$ & $-0,68^{* *}$ & $-0,51^{* *}$ & $-0,41^{*}$ & & \\
EP & $0,58^{* *}$ & $-0,16$ & $0,74^{* *}$ & 0,23 & $0,87^{* *}$ & $-0,53 * *$ & \\
EC & 0,10 & 0,14 & $-0,05$ & $-0,14$ & 0,23 & 0,24 & $-0,05$ \\
\hline
\end{tabular}

$\mathrm{PTF}=$ produtividade total $(\mathrm{t} / \mathrm{ha})\{$ total fruit yield $(\mathrm{t} / \mathrm{ha})\} ; \mathrm{NFP}=$ número de frutos por planta (number of fruits per plant); $\mathrm{CFR}=$ comprimento dos frutos $(\mathrm{cm})\{$ fruit length $(\mathrm{cm})\} ; \mathrm{LFR}=$ largura dos frutos $(\mathrm{cm})\{$ fruit width $(\mathrm{cm})\} ; \mathrm{TSS}=$ teor de sólidos solúveis $\left({ }^{\circ} \mathrm{Brix}\right)$ \{total soluble solids $\left.\left({ }^{\circ} \mathrm{Brix}\right)\right\} ; \mathrm{EP}=$ espessura da polpa dos frutos $(\mathrm{mm})\{$ fruit pulp thickness $(\mathrm{mm})\} ; \mathrm{EC}=$ espessura da casca dos frutos $(\mathrm{mm})$ \{thickness of the fruit cortex $(\mathrm{mm})\} .{ }^{*} \mathrm{e}^{* * \text { Significativo }}$ a 5 e $1 \%$ de probabilidade pelo teste $t$ (significant at 5 and $1 \%$ probability by $t$ test).

experimental também se caracterizou por apresentar maiores valores para NFP, MMF, EP, LFR e reduzida EC. No entanto, não apresentou um valor elevado no TSS $\left(17,01^{\circ}\right.$ Brix $)$, refletindo as correlações predominantemente observadas para esse caráter (Tabela 2). Todavia este híbrido ainda possui TSS satisfatório para ser considerado fruto de alta qualidade, mínimo de $17^{\circ}$ Brix, conforme proposto por Santos et al. (2012). Os frutos deste híbrido experimental foram classificados entre os mais largos do ensaio, porém não tão compridos, entretanto superam a testemunha 'Jabras'. Produtividades máximas de 24,3 e 23,6 t/ha foram observadas para os híbridos 'ESAL 7511' (C. maxima) $x$ 'Canhão' (C. moschata) e 'ESAL 7511' $x$ 'Menina Brasileira' (C. moschata) em Três Pontas-MG (Cheng et al., 1985). O híbrido 'CNPH 1960' também se destacou positivamente, apresentando a terceira melhor produtividade deste experimento, elevado NFR (frutos acima de $2 \mathrm{~kg}$ ) e elevados valores de CFR, LFR, TSS, EP e EC, semelhante aos valores apresentadas pelo híbrido Jabras (Tabela 1). Os híbridos 'CNPH 1992' e ‘CNPH 1359' também apresentaram boa produtividade, frutos grandes e elevado número de frutos por planta; porém menor EP. 'CNPH 1992' apresentou maior EC e 'CNPH 1359' maior TSS. Os demais híbridos apresentaram produtividades intermediárias, sendo agrupados com 'Jabras'. Os híbridos desse grupo apresentaram grande NFP, porém frutos com menores EP, CFR, LFR e, em geral, maiores TSS, confirmando os resultados das correlações e reforçando a dificuldade, do ponto de vista do melhoramento genético, de aliar em um único genótipo as características de elevada produtividade, frutos grandes e elevados valores para TSS.

O presente estudo indicou que existe variabilidade entre os híbridos para as características avaliadas. Foi observada uma predominância de variação genotípica em relação à fenotípica para a maioria das características avaliadas. $\mathrm{O}$ rendimento de frutos se mostrou correlacionado positivamente com maior número de frutos por planta, maior massa média de frutos, maior espessura de polpa e maior largura de frutos. Em contrapartida, o rendimento de frutos não se mostrou correlacionado com comprimento de frutos. Com algumas exceções, frutos com maior massa média apresentaram menor TSS. O híbrido experimental com maior produtividade de frutos foi resultante do cruzamento entre a linhagem feminina CNPH 0739 e a linhagem masculina CNPH 2377. Este híbrido também se caracteriza por apresentar grande número de frutos por planta, massa média de frutos, espessura de polpa e reduzida espessura de casca; 
no entanto não possui elevado valor do TSS. Os híbridos CNPH 1960 e CNPH 1359 também se destacaram positivamente, apresentando boa produtividade, elevado número de frutos por planta (frutos acima de $2 \mathrm{~kg}$ ), elevados valores de comprimento e largura de frutos. Os valores de TSS, EP e EC foram semelhantes ou superiores aos valores apresentados pelo híbrido Jabras. Neste contexto, os resultados indicam boas e promissoras perspectivas no sentido de se obter, a partir desse germoplasma experimental, materiais genéticos do segmento varietal Tetsukabuto com uma combinação de características agronômicas de interesse e aptidão para o cultivo no Brasil Central.

\section{REFERÊNCIAS}

ALMEIDA, AHB; PEDROSA, JF; NOGUEIRA, ICC; NEGREIROS, MZ. 1994. Avaliação de cultivares e híbridos de Cucurbita maxima Duch. e Cucurbita mostacha Duch. na microrregião salineira do Rio Grande do Norte. Caatinga 8: 45-48.

AMARANTE, CVT; MACEDO, AF. 2000. Frutificação e crescimento de frutos em abóbora híbrida 'Tetsukabuto' tratada com alfanaftalenoacetato de sódio. Horticultura Brasileira 18: 212-214.

AMARO, GB; RESENDE, FV; CARVALHO, ADF; LOPES, JF; LIMA, MF; MICHEREFF, MF. 2012. Desempenho de cultivares de abóbora japonesa no cultivo orgânico. Horticultura Brasileira 30: S5518-S5523 (Suplemento CD Rom).

BARBOSA, GS. 2009. Desempenho agronômico, caracterização morfológica e polínica de linhagens de abóbora (Cucurbita moschata) com potencial para o lançamento de cultivares. Campos dos Goytacazes: UENF. 110p (Tese mestrado).

BEE, RA; BARROS, ACSA. 1999. Sementes de abóbora armazenadas em condições de vácuo. Revista Brasileira de Sementes 21: 120-126.

BEZERRA-NETO, FV; LEAL, NR; COSTA, FR; GONÇALVES, GM; AMARAL-JÚNIOR, AT; VASCONCELLOS, HO; MELLO, M. 2006. Análise biométrica de linhagens de abóbora. Horticultura Brasileira 24: 378-380.

BISOGNIN, DA. 2002. Origin and evolution of cultivated cucurbits. Ciência Rural 32: 715-723.

BOITEUX, LS; NASCIMENTO, WM; FONSECA, MEN; REIS, A; LOPES, JF; MENDONÇA, JL; REIFSCHNEIDER, FJB. 2007. Brasileirinha: Cultivar de abóbora (Cucurbita moschata) de frutos bicolores com valor ornamental e aptidão para consumo verde. Horticultura Brasileira 25: 103-106.

CHENG, SS; PEDROSA, J; CHU, EY. 1985. Avaliação de híbridos $\mathrm{F}_{1}$ de Cucurbita maxima ESAL $7511 \times$ Cucurbita spp. Horticultura Brasileira 3: 35-36.

COSTA, CJ; CARMONA, R; NASCIMENTO, WM. 2006. Idade e tempo de armazenamento de frutos e qualidade fisiológica de sementes de abóbora híbrida. Revista Brasileira de Sementes 28: 127-132.

CRUZ, CD. 2006. Programa Genes: biometria: UFV. 382p.

EMBRAPA - Empresa Brasileira de Pesquisa Agropecuária. 2014, 02 de abril. 'Jabras'Hibrido Nacional de Abóbora Tetsukabuto. Disponível em: http://www.cnph.embrapa.br/ cultivares/jabras.htm

IBGE. Censo Agropecuário, 2006. Abóboras (Morangas e Jerimum). Quantidade produzida, área e número de informantes, Brasil e Unidades da Federação. Rio de Janeiro. Disponível em: http://www.sidra.ibge.gov.br/ bda/tabela/protabl.asp?c $=822 \& \mathrm{z}=\mathrm{t} \& \mathrm{O}=1 \& \mathrm{i}=\mathrm{P}$

IRVING, DE; HURST, PL; RAGG, JS. 1997. Changes in carbohydrates and carbohydrate metabolizing enzymes during the development, maturation and ripening of Buttercup squash (Cucurbita maxima D. "Delica"). Journal of the American Society for Horticultural Science 122: 310-314.

KARAAĞAÇ, O; BALKAYA, A. 2013. Interspecific hybridization and hybrid seed yield of winter squash (Cucurbita maxima Duch.) and pumpkin (Cucurbita moschata Duch.) lines for rootstock breeding. Scientia
Horticulturae 149: 9-12.

MAYNARD, DN; ELMSTROM, GW; TALCOTT, ST; CARLE, RB. 2002. "El Dorado" and "La Estrella": Compact plant tropical pumpkin hybrids. HortScience 37: 831-833.

MIRANDA, FFR. 2012. Efeito da frutificação induzida por 2, 4-D em características agronômicas dos frutos de abóbora 'Tetsukabuto'. Palmas-TO: UFT. $62 \mathrm{p}$ (Dissertação mestrado).

NASCIMENTO, WM; COIMBRA, KG; FREITAS, RA; BOITEUX, LS. 2008. Eficiência de acessos de Cucurbita maxima como polinizadores de abóbora híbrida do tipo 'Tetsukabuto'. Horticultura Brasileira 26: $540-542$

PASQUALETTO, A; SILVA, NF; ORDONEZ, GP; BARCELOS, RW. 2001. Produção de frutos de abóbora híbrida pela aplicação de 2,4-D nas flores. Pesquisa Agropecuária Tropical 31: 23-27.

QUEIROZ, MA. 2004. Germplasm of Cucurbitaceae in Brazil. Crop Breeding and Applied Biotechnology 4: 377-383.

RESENDE, GM; BORGES, RME; GONÇALVES, NPS. 2013. Produtividade da cultura da abóbora em diferentes densidades de plantio no Vale do São Francisco. Horticultura Brasileira 31: 504-508.

SANTOS, MR; SEDIYAMA, MAN; MOREIRA, MA; MEGGUER, CA; VIDIGAL, SM. 2012. Rendimento, qualidade e absorção de nutrientes pelos frutos de abóbora em função de doses de biofertilizante. Horticultura Brasileira 30: 160-167.

SILVA, TB. 2010. Seleção, comportamento fenotípico e genotípico e desenvolvimento de uma nova cultivar de abóbora (Cucurbita moschata Dusch). São Cristóvão: UFS-SE. 46p (Dissertação mestrado).

YONGAN, C; BINGKUI, Z; ENHUI, Z; ZUNLIAN, Z. 2002a. Study on affinity of sexual hybridization between Cucurbita maxima D. and Cucurbita moschata D. Cucurbit Genetics Cooperative Report 25: 54-55.

YONGAN, C; BINGKUI, Z; ENHUI, Z; ZUNLIAN, Z. 2002b. Germplasm innovation by interspecific crosses in pumpkin. Cucurbit Genetics Cooperative Report 25: 56-57. 